Article

\title{
Two New Withanolide Lactones from Flos Daturae
}

\section{Hai-Xue Kuang *, Bing-You Yang, Yong-Gang Xia and Qiu-Hong Wang}

Key Laboratory of Chinese Materia Medica, Heilongjiang University of Chinese Medicine, Ministry of Education, Harbin 150040, China

* Author to whom correspondence should be addressed; E-Mail: hxkuang@hotmail.com; Tel.: +86 45182193001; Fax: +86 45182110803 .

Received: 1 June 2011; in revised form: 29 June 2011 / Accepted: 5 July 2011 /

Published: 11 July 2011

\begin{abstract}
Chemical investigation of the 50\% ethanol eluate fraction from a macroporous resin of flowers of Datura metel L. collected in the Jiangsu Province of China resulted in the isolation of two new withanolides, baimantuoluoline $\mathrm{G}(\mathbf{1})$ and baimantuoluoside $H(2)$. Their structures were elucidated as $(12 \beta, 6 \beta, 22 R)-1,10$-seco-6,12,27-trihydroxy-26-oxowitha-3,5,24-trienolide-1-oic acid- $\varepsilon$-lactone (1) and $(5 \beta, 6 \alpha, 12 \beta, 22 R)-5,6,12,27$-tetrahydroxy-1,26-dioxo-witha-2,24-dienolide-27-O- $\beta$-glucopyranoside (2) on the basis of extensive spectroscopic analysis (1D, 2D-NMR and HRESIMS) and chemical studies.
\end{abstract}

Keywords: Flos Daturae; Datura metel L.; withanolide lactones

\section{Introduction}

Flos Daturae is the dry flower of Datura metel L. (Solanaceae), which widely distributed in China [1]. Flos Daturae, known as "baimantuoluo" or "yangjinhua" in China, has been used for centuries in Traditional Chinese Medicine for the treatment of asthma, convulsions, pain, and rheumatism [2]. Flos Daturae has been found to be rich in tropane alkaloids [2]. Besides, a number of withanolides have also been isolated from Flos Daturae [3-8]. Recently Flos Daturae has been used clinically for the treatment of psoriasis in China [9]. The effective part for psoriasis, namely the non-alkaloid water-soluble fraction of Flos Daturae, has been demonstrated to have anti-inflammatory, anti- skin titillation and anti-anaphylaxis actions by detailed pharmacological experiments [9]. However, its active constituents and pharmacological effects related to the treatment of psoriasis were not fully elucidated. As a part of a continuing project to study the active constituents of Flos Daturae for psoriasis [6-8], we investigated 
the $50 \%$ ethanol eluate fraction from a macroporous resin of the flowers of $D$. metel. Our extraction and separation method can greatly enrich fractions in withanolide compounds so trace withanolides can be isolated. In this paper, we present the isolation and structural characterization of the two new withanolide lactones (Figure 1) on the basis of the interpretation of spectral data, including 1D, 2D NMR and HRESIMS data. A 1,10-seco withanolide is reported from only the third time in herb plants.

Figure 1. Structures of 1 and 2.
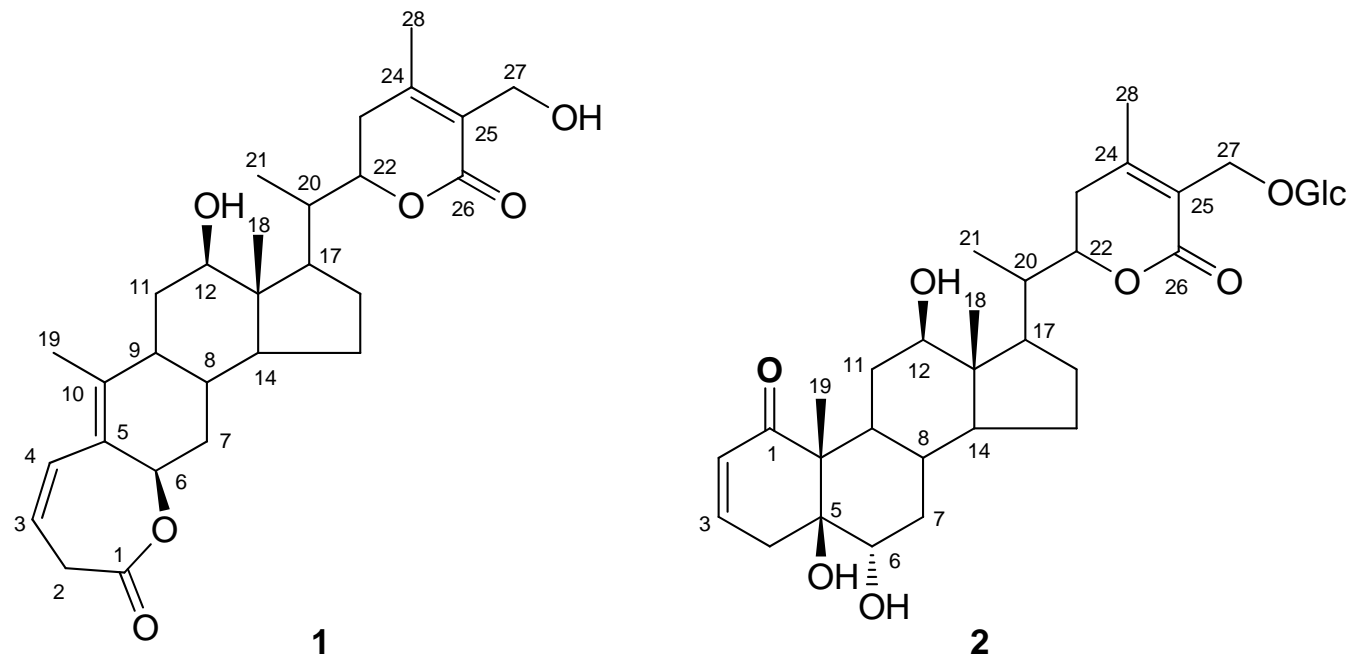

\section{Results and Discussion}

Compound 1 was obtained as a white amorphous powder. Its molecular formula was established as $\mathrm{C}_{28} \mathrm{H}_{38} \mathrm{O}_{6}$ by the positive HRESIMS, indicating six degrees of unsaturation. The ${ }^{1} \mathrm{H}-\mathrm{NMR}$ spectrum of 1 (Table 1), showed several characteristic signals of the common withanolide steroid. Three signals at $\delta 0.78(3 \mathrm{H}, s), 1.18(3 \mathrm{H}, d, J=6.8 \mathrm{~Hz}), 1.84(3 \mathrm{H}, s)$ and $2.10(3 \mathrm{H}, s)$ were attributed to Me-18, Me-21, Me-19 and Me-28, respectively. A Me-27 signal was missing, and was replaced by two doublets at $\delta 4.37(1 \mathrm{H}, d, J=11.7 \mathrm{~Hz})$ and $4.30(1 \mathrm{H}, d, J=11.7 \mathrm{~Hz})$, suggesting that $\mathrm{C}-27$ was substituted by hydroxyl group. The double doublet at $\delta 3.47(1 \mathrm{H}, d d, J=10.9,4.5 \mathrm{~Hz})$ was characteristic for a $12 \beta$-hydroxywithanolide [4]. $\mathrm{H}-22$ resonated as a double triplet at $\delta 4.62(1 \mathrm{H}, d t, J=12.9,3.4 \mathrm{~Hz})$, revealing a $R$ configuration at $\mathrm{C}-22[5,6]$.

The ${ }^{13} \mathrm{C}-\mathrm{NMR}$ spectrum of $\mathbf{1}$ showed resonances for all 28 carbons. The characteristic downfield signal at $\delta 175.5$ was due to two lactone carbonyls, respectively, along with the characteristic doublets at $\delta 126.3,157.9$ and 168.6 were attributed to $\mathrm{C}-24, \mathrm{C}-25$ and $\mathrm{C}-26$ of the $\alpha, \beta$-unsaturation- $\gamma$-lactone ring respectively, in the ring $\mathrm{E}$. The signals at $\delta 118.1,130.2,126.5$ and 142.5 for the vinylic carbons at C-3, C-4, C-5, C-10 respectively, in the ring A. The typical signals at $\delta 74.8,78.6,80.8$, and 56.3 were assigned to the oxygenated carbons at C-6, C-12, C-22 and C-27, respectively. The signals appearing at $\delta 8.1,15.6,15.3$ and 20.2 were assigned to the Me-18, Me-19, Me-21 and Me-28, respectively. In addition, a signal at $\delta_{\mathrm{H}} 5.30(1 \mathrm{H}, b r . s)$ together with the signal in the ${ }^{13} \mathrm{C}$ NMR spectrum of a keto-carbonyl of C-1 upfield of $\delta_{\mathrm{C}} 175.5$ due to an ester group of $\mathrm{CO}-\mathrm{O}-\mathrm{CH}$ indicated that 1 possesses a 1,10-seco-steroid skeleton [10,11]. Further support this assumption was obtained from the fact that the methylene protons at $\mathrm{C}-2[\delta 4.03(1 \mathrm{H}, b r . d, J=17.4 \mathrm{~Hz})$ and $3.08(1 \mathrm{H}, d d, J=17.4,8.7 \mathrm{~Hz})]$ were 
unusually shifted to a low field, suggesting the methylene to be situated between an ester carbonyl group and carbon-carbon double bond. Based on this finding and HMBC correlations, between $\mathrm{C}-1$ $\left(\delta_{\mathrm{C}} 175.5\right)$ and $\mathrm{H}-2 \alpha, \mathrm{H}-2 \beta$, and H-3, between $\mathrm{H}-4(6.62(1 \mathrm{H}, d d, J=11.4,3.1 \mathrm{~Hz})$ and C-2, C-5, C-6, and $\mathrm{C}-10$, and between $\mathrm{C}-5$ and Me-19, as shown in Figure 2. Thus, a seven-membered $\beta$, $\gamma$-unsaturated lactonic moiety was determined in ring $\mathrm{A}$.

The $\beta$-configuration of the lactone bond at C-6 was established by a NOESY experiment (Figure 2). The NOESY spectrum showed the correlation between $\mathrm{H}-6(1 \mathrm{H}, b r . s)$ and $\mathrm{H}-2 \alpha, \mathrm{H}-7 \alpha$ and $\mathrm{H}-7 \beta$, indicating that H-6 has the same configuration as $\mathrm{H}-2 \alpha$. Since a small coupling between $\mathrm{H}-2 \alpha$ and $\mathrm{H}-3$ in the ${ }^{1} \mathrm{H}$ NMR spectrum was observed due to an approximate $90^{\circ}$, a $\beta$-configuration of the lactone bond at C- 6 was inferred, which is in agreement with those of 1,10 -seco steroids [10,11]. Therefore, the structure of 1 was deduced as (12 $\beta, 6 \beta, 22 R)$-1,10-seco-6,12,27-trihydroxy-26-oxo-witha-3,5,24trienolide-1-oic acid- $\varepsilon$-lactone, which was named baimantuoluoline $\mathrm{G}$.

Table 1. ${ }^{1} \mathrm{H}$ and ${ }^{13} \mathrm{C}-\mathrm{NMR}$ data of $\mathbf{1}$ and 2 in $\mathrm{CD}_{3} \mathrm{OD}$ at $400 \mathrm{MHz}$ and $100 \mathrm{MHz}, J$ in $\mathrm{Hz}$.

\begin{tabular}{|c|c|c|c|c|}
\hline \multirow{2}{*}{ No. } & \multicolumn{2}{|l|}{1} & \multicolumn{2}{|l|}{2} \\
\hline & $\delta_{\mathrm{H}}$ & $\delta_{\mathrm{C}}$ & $\delta_{\mathrm{H}}$ & $\delta_{\mathrm{C}}$ \\
\hline 1 & & 175.5 & & 207.0 \\
\hline \multirow[t]{2}{*}{2} & $4.03(1 \mathrm{H}, b r . d, J=17.4, \alpha-\mathrm{H})$ & 35.9 & $5.77(1 \mathrm{H}, d d, J=10.0,2.4)$ & 128.9 \\
\hline & $3.08(1 \mathrm{H}, d d, J=17.4,8.7, \beta-\mathrm{H})$ & & & \\
\hline 3 & $5.53(1 \mathrm{H}, d d, J=11.4,8.7)$ & 118.1 & $6.66(1 \mathrm{H}, d d d, J=10.0,5.2,2.0)$ & 143.5 \\
\hline \multirow[t]{2}{*}{4} & $6.62(1 \mathrm{H}, d d, J=11.4,3.1)$ & 130.2 & $3.24(1 \mathrm{H}, d t, J=20.0,2.4)$ & 36.5 \\
\hline & & & $2.05(1 \mathrm{H}, d d, J=20.0,5.2)$ & \\
\hline 5 & & 126.5 & & 78.2 \\
\hline 6 & $5.30(1 \mathrm{H}, b r . s)$ & 74.8 & $3.52(1 \mathrm{H}, t, J=2.0)$ & 75.2 \\
\hline \multirow[t]{2}{*}{7} & $2.03(1 \mathrm{H}, m)$ & 33.7 & & 33.8 \\
\hline & $1.43(1 \mathrm{H}, m)$ & & & \\
\hline 8 & $1.50(1 \mathrm{H}, m)$ & 33.5 & & 30.5 \\
\hline 9 & $1.77(1 \mathrm{H}, m)$ & 47.2 & $1.87(1 \mathrm{H}, m)$ & 41.0 \\
\hline 10 & & 142.5 & & 52.8 \\
\hline \multirow[t]{2}{*}{11} & $2.14(1 \mathrm{H}, d t, J=16.1,4.2)$ & 36.9 & $2.42(1 \mathrm{H}, d t, J=12.4,4.0)$ & 33.8 \\
\hline & $1.36(1 \mathrm{H}, m)$ & & $1.36(1 \mathrm{H}, m)$ & \\
\hline 12 & $3.47(1 \mathrm{H}, d d, J=10.9,4.5)$ & 78.6 & $3.47(1 \mathrm{H}, d d, J=11.2,4.4)$ & 78.7 \\
\hline 13 & & 49.1 & & 49.0 \\
\hline 14 & $1.25(1 \mathrm{H}, m)$ & 53.8 & $1.25(1 \mathrm{H}, m)$ & 55.3 \\
\hline \multirow[t]{2}{*}{15} & $1.72(1 \mathrm{H}, m)$ & 23.8 & $1.76(1 \mathrm{H}, m)$ & 24.6 \\
\hline & $1.30(1 \mathrm{H}, m)$ & & $1.31(1 \mathrm{H}, m)$ & \\
\hline \multirow[t]{2}{*}{16} & $1.73(1 \mathrm{H}, m)$ & 27.7 & $1.76(1 \mathrm{H}, m)$ & 27.6 \\
\hline & $1.60(1 \mathrm{H}, m)$ & & $1.54(1 \mathrm{H}, m)$ & \\
\hline 17 & $1.61(1 \mathrm{H}, m)$ & 54.5 & $1.56(1 \mathrm{H}, m)$ & 55.0 \\
\hline 18 & $0.78(3 \mathrm{H}, s)$ & 8.1 & $0.76(3 \mathrm{H}, s)$ & 8.0 \\
\hline 19 & $1.84(3 \mathrm{H}, s)$ & 15.6 & $1.30(3 \mathrm{H}, s)$ & 16.1 \\
\hline 20 & $2.01(1 \mathrm{H}, m)$ & 38.9 & $2.05(1 \mathrm{H}, m)$ & 38.9 \\
\hline 21 & $1.18(3 \mathrm{H}, d, J=6.8)$ & 15.3 & $1.18(3 \mathrm{H}, d, J=6.8)$ & 15.5 \\
\hline 22 & $4.62(1 \mathrm{H}, d t, J=12.9,3.4)$ & 80.8 & $4.60(1 \mathrm{H}, d t, J=13.6,4.0)$ & 80.9 \\
\hline
\end{tabular}


Table 1. Cont.

\begin{tabular}{lllll}
\hline 23 & $2.55(1 \mathrm{H}, d d, J=18.0,13.2)$ & 32.5 & $2.58(1 \mathrm{H}, d d, J=18.0,13.2)$ & 32.3 \\
& $2.24(1 \mathrm{H}, d d, J=18.0,3.2)$ & & $2.21(1 \mathrm{H}, d d, J=18.0,3.2)$ & \\
24 & & 157.9 & & 160.5 \\
25 & & 126.3 & & 123.6 \\
26 & & 168.6 & & 168.7 \\
27 & $4.37(1 \mathrm{H}, d, J=11.7)$ & 56.3 & $4.46(1 \mathrm{H}, d, J=10.8)$ & 63.5 \\
& $4.30(1 \mathrm{H}, d, J=11.7)$ & & $4.61(1 \mathrm{H}, d, J=10.8)$ & \\
28 & $2.10(3 \mathrm{H}, s)$ & 20.2 & $2.13(3 \mathrm{H}, s)$ & 20.8 \\
$1^{\prime}$ & & & $4.31(1 \mathrm{H}, d, J=8.0)$ & 103.9 \\
$2^{\prime}$ & & & $3.16(1 \mathrm{H}, t, J=8.0)$ & 75.0 \\
$3^{\prime}$ & & & $3.26(1 \mathrm{H}, m)$ & 78.0 \\
$4^{\prime}$ & & & $3.29(1 \mathrm{H}, m)$ & 71.5 \\
$5^{\prime}$ & & & $3.24(1 \mathrm{H}, m)$ & 62.7 \\
$6^{\prime}$ & & & $3.85(1 \mathrm{H}, d d, J=12.0,2.0)$ & \\
& & & $3.67(1 \mathrm{H}, d d, J=12.0,5.2)$ & \\
\hline
\end{tabular}

Figure 2. Key ${ }^{1} \mathrm{H}-{ }^{1} \mathrm{H}$ COSY and HMBC correlations of $\mathbf{1}$.
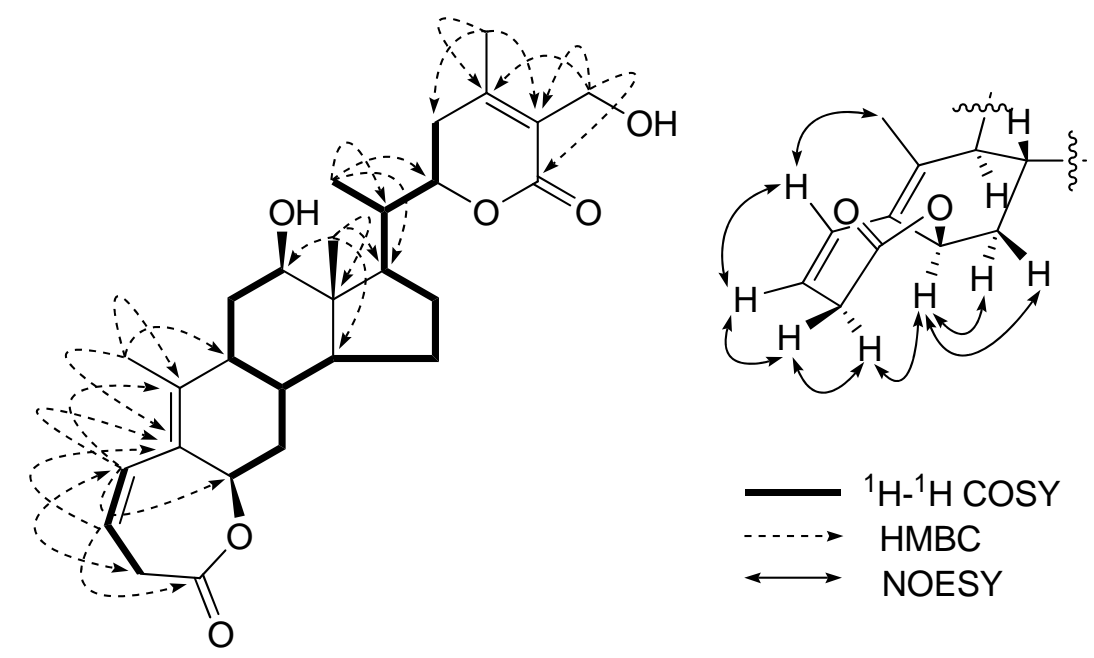

Compound 2 was obtained as a white amorphous powder and showed positive results for the Molish reagent, which was indicative of a withanolide glycoside. Its molecular formula was established as $\mathrm{C}_{34} \mathrm{H}_{50} \mathrm{O}_{12}$ by the positive HRESIMS, indicating 10 degrees of unsaturation. The ${ }^{1} \mathrm{H}-\mathrm{NMR}$ spectrum of 2 showed distinct resemblance to those of baimantuoluoside $\mathrm{G}((5 \alpha, 6 \beta, 22 \mathrm{R})-5,6,27$-trihydroxy-1oxowitha-2,24-dienolide-27-O- $\beta$-glucopyranoside) [6]. The only notable difference was the change of $\mathrm{H}-12$ signal appeared as a double doublet at $\delta 3.47(1 \mathrm{H}, d d, J=11.2,4.4 \mathrm{~Hz})$, indicating that $\mathrm{C}-12$ was substituted by a hydroxyl group. The ${ }^{13} \mathrm{C}$-NMR (DEPT) spectrum showed an additional downfield $\mathrm{C}$-atom signal at $\delta \mathrm{C} 78.7$ in 2, which was affirmatively assigned to the $\mathrm{C}-12$. On the basis of above data, the structure of 2 was identified to be $(5 \beta, 6 \alpha, 12 \beta, 22 R)-5,6,12,27$-tetrahydroxy-1,26-dioxo-witha2,24-dienolide-27-O- $\beta$-glucopyranoside, and was named baimantuoluoside $\mathrm{H}$. 


\section{Experimental}

\subsection{General}

Preparative HPLC (Waters, Delta 600-2487) was performed on a Hypersil-ODS II (10 $\mu$, $20 \times 300 \mathrm{~mm}$, Yilite, Dalian, People's Republic of China) with Waters Empower software. IR spectra were measured in $\mathrm{KBr}$ discs on a Shimadzu FTIR-8400S spectrometer. HRESIMS were carried out on Waters Xevo QTOF mass spectrometer with Masslynx V4.11 software. NMR data were recorded in $\mathrm{CD}_{3} \mathrm{OD}$ on Bruker DPX 400 spectrometer at $400 \mathrm{MHz}$ for $\left({ }^{1} \mathrm{H}\right)$ and $100 \mathrm{MHz}\left({ }^{13} \mathrm{C}\right)$ with Xwin-NMR software version 2.6; chemical shifts $\delta$ in ppm rel. to $\mathrm{SiMe}_{4}$ as internal standard, coupling constant $J$ in Hz. The pulse conditions were as follows: for the ${ }^{1} \mathrm{H}-\mathrm{NMR}$ spectra, spectrometer frequency (SF) 400.13 MHz, acquisition time (AQ) 2.0447731s, number of transients (NS) 64, receiver gain (RG) 128, temperature (TE) $303.0 \mathrm{~K}$, dwell time (DW) $62.400 \mu \mathrm{s}$, per scan delay (DE) $7.00 \mu \mathrm{s}$, dummy scans (DS) 0; for the ${ }^{13} \mathrm{C}-\mathrm{NMR}$ spectrum, SF $100.62 \mathrm{MHz}$, AQ $0.65 \mathrm{~s}$, NS 1430, RG 14596.5, TE 303.0 K, DW $19.900 \mu \mathrm{s}$, DE $28.00 \mu \mathrm{s}$, DS 0; for the COSY spectrum, SF 400.13 MHz, NS 16, DS 16, pulse (P1) $10.8 \mu \mathrm{s}$, TE 303.0 K, RG 574.7, DW $170.400 \mu \mathrm{s}$, DE $7.00 \mu \mathrm{s}$; for the NOE experiments, SF $400.13 \mathrm{MHz}$, NS 64, DE $7.00 \mu \mathrm{s}$; for the HMBC spectrum, SF $400.13 \mathrm{MHz}$, AQ $0.1745396 \mathrm{~s}$, RG 16384, NS 64, DW $170.400 \mu \mathrm{s}$, DS 16, DE 7.00 $\mu$, TE $303.0 \mathrm{~K}$; and for the HSQC spectrum, SF 400.13 MHz, AQ 0.1745396 s, NS 32, DS 16, DE $7.00 \mu \mathrm{s}$, DW 170.400 $\mu \mathrm{s}$, RG 16384, TE $303.0 \mathrm{~K}$.

\subsection{Plant Material}

The dry flowers of $D$. metel were collected in Nanjing city of Jiangsu Province of China in September 2002, and identified by Prof. Zhenyue Wang. A voucher specimen (No. 2002035) is deposited at the Herbarium of Heilongjiang University of Chinese Medicine, China.

\subsection{Extraction and Isolation}

The dried flowers $(30 \mathrm{~kg})$ of $D$. metel L. were extracted with $70 \% \mathrm{EtOH}$ under reflux $(2 \times 100 \mathrm{~L})$ for $2.5 \mathrm{~h}$ (each), and the combined solution was filtered and evaporated under vacuum to a syrup $\left(45{ }^{\circ} \mathrm{C}\right)$, followed by suspension in $\mathrm{H}_{2} \mathrm{O}(500 \mathrm{~L})$. The suspension was acidified with $0.1 \% \mathrm{HCl}$, and then filtered and exchange for Styrene-DVB $(001 \times 7)$. The exchanged solution was passed through AB-8 crosslinked polystyrene, and sequentially eluted with $\mathrm{H}_{2} \mathrm{O}, 50 \% \mathrm{EtOH}$, and 95\% EtOH, respectively. $50 \% \mathrm{EtOH}$ elution was concentrated under vacuum to yield a syrup (52.0 g) and this crude residue was subjected to silica gel $(300 \mathrm{mesh}, 50 \times 8 \mathrm{~cm}$, flow rate $10 \mathrm{~mL} / \mathrm{min})$ and eluted successively with $6 \mathrm{~L}$ of $\mathrm{CHCl}_{3} / \mathrm{MeOH}$ during each gradient $(10: 1 \rightarrow 1: 1)$ to give 10 fractions (Fr. 1-10). Fr. 7 (5 g) continues silica gel chromatography (300 mesh, $10 \times 2 \mathrm{~cm}$, flow rate $1 \mathrm{~mL} / \mathrm{min}$ ) eluted with $600 \mathrm{~mL}$ of $\mathrm{CHCl}_{3} / \mathrm{MeOH}$ during each gradient $(5: 1 \rightarrow 1: 1)$ to afford a number of sub-fractions $\mathrm{A}_{1}-\mathrm{A}_{13}$. Compounds $1\left(15 \mathrm{mg}, t_{\mathrm{R}}=37.2 \mathrm{~min}\right)$ and $2\left(21 \mathrm{mg}, t_{\mathrm{R}}=12.3 \mathrm{~min}\right)$ were obtained from the sub-fraction $\mathrm{A}_{4}(0.9 \mathrm{~g})$ with $\mathrm{MeOH} / \mathrm{H}_{2} \mathrm{O}(2: 3)$ by prep. HPLC chromatography on a Hypersil-ODS II column $(10 \mu \mathrm{m}$, $20 \times 300 \mathrm{~mm}$, flow rate $8 \mathrm{~mL} / \mathrm{min}$ ). 
Baimantuoluoline $G(\mathbf{1})$. White amorphous powder, $[\alpha]^{25}{ }_{\mathrm{D}}=+17.0(\mathrm{c}=0.1, \mathrm{MeOH})$. IR $(\mathrm{KBr})$ : $v_{\max }=3426,2925,1708,1387,1286,1135,1089,995 \mathrm{~cm}^{-1}$. HRESIMS (positive): $\mathrm{m} / z=493.2578$ (calc. for $\mathrm{C}_{28} \mathrm{H}_{38} \mathrm{NaO}_{6}, 493.2566,[\mathrm{M}+\mathrm{Na}]^{+}$) and 509.2327 (calc. for $\mathrm{C}_{28} \mathrm{H}_{38} \mathrm{KO}_{6}, 509.2305,[\mathrm{M}+\mathrm{K}]^{+}$). ${ }^{1} \mathrm{H}$ - and ${ }^{13} \mathrm{C}-\mathrm{NMR}$ : see Table 1.

Baimantuoluoside $\mathrm{H}(2)$ : White amorphous powder, $[\alpha]_{\mathrm{D}}^{25}=+24(\mathrm{c}=0.1, \mathrm{MeOH})$. IR $(\mathrm{KBr})$ : $v_{\max }=3411,3326,2942,2923,2865,2590,1670,1070,1030 \mathrm{~cm}^{-1}$. HRESIMS (positive): $m / z=673.3224$ (calc. for $\mathrm{C}_{34} \mathrm{H}_{50} \mathrm{NaO}_{12}, 673.3200,[\mathrm{M}+\mathrm{Na}]^{+}$) and 689.2948 (calc. for $\mathrm{C}_{34} \mathrm{H}_{50} \mathrm{KO}_{12}$, 689.2939, $\left.[\mathrm{M}+\mathrm{K}]^{+}\right) .{ }^{1} \mathrm{H}-$ and ${ }^{13} \mathrm{C}-\mathrm{NMR}$ : see Table 1.

\section{Conclusions}

Withanolide lactones constitute a group of C28 steroidal lactones isolated from several genera of Solananceae [3]. A characteristic feature of their skeleton is the (mostly) $\alpha, \beta$-unsaturated $\delta$-lactone ring formed in the side chain [3], which has been reported to be associated with diverse biological activities including cytotoxic, anti-inflammatory, antioxidant, and antitumor properties [4]. As a part of our chemical investigation on $D$. metel, we have isolated two new withanolide lactones. Their structures were established on the basis of spectroscopic evidence. Compound $\mathbf{1}$ is a novel withanolide lactone obtained from a $D$. metel with an unusual seven-membered $\beta, \gamma$-unsaturated lactone of ring A.

\section{Acknowledgements}

Our work was supported by the Major State Basic Research Development Program of China (973 Program 2006CB504708) the National Natural Science Foundation of China (No. 30371736, 30672633) and Special Fund Project of National Excellent Doctoral Dissertation of China (200980).

\section{Conflict of Interest}

The authors declare no conflict of interest.

\section{References}

1 Missouri Botanical Garden. Tropicos. Available online: http://www.tropicos.org/NameSearch.aspx (accessed on 28 May 2011).

2 Jiangsu New Medical College. Zhong Yao Da Ci Dian; Shanghai Science and Technology Press: Shanghai, China, 1986; Volume 2, p. 1719.

3 Glotter, E.; Kirson, I.; Abraham, A.; Lavie, D. Constituents of Withania somnifera Dun.-XIII The withanolides of chemotype III. Tetrahedron 1973, 29, 1353-1364.

4 Pan, Y.H.; Wang, X.C.; Hu, X.M. Cytotoxic withanolides from the flowers of Datura metel. J. Nat. Prod. 2007, 70, 1127-1132.

5 Ma, L.; Xie, C.M.; Li, J.; Lou, F.C.; Hu, L.H. Daturametelins H, I, and J: three new withanolide glycosides from Datura metel L. Chem. Biodiv. 2006, 3, 180-186.

6 Yang, B.Y.; Xia, Y.G.; Wang, Q.H.; Kuang, H.X. Baimantuoluosides D-G, Four new withanolide glucosides from the flower of Datura metel L. Arch. Pharm. Res. 2010, 33, 1143-1148. 
7 Kuang, H.X.; Yang, B.Y.; Tang, L.; Xia, Y.G.; Dou, D.Q. Baimantuoluosides A-C, Three New Withanolide Glucosides from the Flower of Datura metel L. Helv. Chim. Acta 2009, 92, 1315-1323.

8 Yang, B.Y.; Wang, Q.H.; Xia, Y.G.; Feng, W.S.; Kuang, H.X. Baimantuoluolines D-F, three new withanolides from the flower of Datura metel L. Helv. Chim. Acta 2008, 91, 964-971.

9 Wang, Q.H.; Xiao, H.B.; Yang, B.Y.; Yao, F.Y.; Kuang, H.X. Studies on pharmacological actions of the effective parts for psoriasis in Flos Daturae (I). Chin. J. Exp. Trad. Med. Form. 2008, 14, 48-51.

10 Fang, S.T.; Liu, J.K.; Li, B. A novel 1,10-seco withanolide from Physalis peruviana. J. Asian Nat. Prod. Res. 2010, 12, 618-622.

11 Kazuo, I.; Makoto, I.; Kinzo, W. Stoloniolide I and II, new marine lactonic steroids with an unprecedented 1,10-secoergostane skeleton, isolated from the Okinawan Soft Coral, Clavularia viridis. Chem. Lett. 1995, 24, 1109-1110.

Sample Availability: Samples of baimantuoluoline G (1) and baimantuoluoside H (2) are available from the authors.

(C) 2011 by the authors; licensee MDPI, Basel, Switzerland. This article is an open access article distributed under the terms and conditions of the Creative Commons Attribution license (http://creativecommons.org/licenses/by/3.0/). 